\title{
Changes in the Sensory Weighting Strategies in Balance Control Throughout Maturation in Children
}

\author{
Solara Sinno, $\mathrm{PhD}^{1,2,3}$ Georges Dumas, $\mathrm{MD}, \mathrm{PhD}^{1,4}$ Art Mallinson, $\mathrm{PhD}^{5}$ Fadi Najem, $\mathrm{PhD}, \mathrm{AuD}^{6,7}$ \\ Kim Smith Abouchacra, $\mathrm{PhD}^{3,6}$ Lewis Nashner, $\mathrm{PhD}^{8}$ Philippe Perrin ${ }^{1,2,9}$
}

${ }^{1}$ EA 3450 DevAH, Development, Adaptation and Handicap, Faculty of

Medicine, University of Lorraine, Vandoeuvre-lès-Nancy, France

Address for correspondence Solara Sinno, PhD,

2 Laboratory for the Analysis of Posture, Equilibrium and Motor Function solara.sinno@univ-lorraine.fr

(LAPEM), University Hospital of Nancy, Vandoeuvre-lès-Nancy, France

${ }^{3}$ Department of Otorhinolaryngology-Head and Neck Surgery,

Audiology \& Balance Center, American University of Beirut Medical

Center, Beirut, Lebanon

${ }^{4}$ Department of Oto-Rhino-Laryngology, Head and Neck Surgery,

Grenoble Alpes University Hospital, Grenoble, France

${ }^{5}$ Neuro-otology Unit, Department of Surgery, Vancouver General Hospital, Faculty of Medicine, University of British Columbia, Vancouver, Canada

${ }^{6}$ Medical Audiology Sciences Program, Division of Health Professions, Faculty of Health Sciences, American University of Beirut, Beirut, Lebanon

${ }^{7}$ Department of Hearing and Speech, Al-Ahliyya Amman University, Amman, Jordan

${ }^{8}$ Biomedical Business Development, Chicago, Illinois

${ }^{9}$ Department of Pediatric Oto-Rhino-Laryngology, University Hospital of Nancy, Vandoeuvre-lès-Nancy, France

J Am Acad Audiol 2021;32:122-136.

\author{
Abstract \\ Keywords \\ - computerized \\ dynamic \\ posturography \\ - sensory organization \\ test \\ - children \\ - normative data \\ - pediatric vestibular \\ evaluation
}

Background The central nervous system integrates information from different sensory inputs (vestibular, visual, and somatosensory) to maintain balance. However, strategies for weighing sensory information change as maturation occurs.

Purpose The purpose of this study was to: (1) evaluate postural control development in a large sample of healthy children aged 5 to 17 years old, (2) analyze changes in sensory weighting strategies as maturation occurs, and (3) determine the extent to which anthropometric characteristics (height, weight, body mass index [BMI]) influence postural control.

Sample Size This study recruited 120 healthy children, equally distributed in gender and number, into four age groups (5-8 years, 9-11 years, 12-14 years, and 15-17 years) and compared them to a control group of 20 healthy adults (aged 20-25 years). Research Design The sensory organization test (SOT) was used to assess overall balance and the use of specific sensory inputs to maintain postural control. All children underwent the six SOT conditions: (1) eyes open, surround and platform stable, (2) eyes closed, surround and platform stable, (3) eyes open, sway-referenced surround, platform stable, (4) eyes open, sway-referenced platform, (5) eyes closed, swayreferenced platform, and (6) eyes open, sway-referenced surround and platform.

Data Analysis Condition-specific equilibrium scores (ES), composite equilibrium scores (CES), and sensory analysis ratios were analyzed to determine whether the received

September 24, 2019

accepted after revision

July 24,2020

published online

December 9, 2020
(C) 2020. American Academy of

Audiology. All rights reserved.

Thieme Medical Publishers, Inc.,

333 Seventh Avenue, 18th Floor,

New York, NY 10001, USA
DOI https://doi.org/ 10.1055/s-0040-1718706. ISSN $1050-0545$. 
performance was related to age, gender, or specific anthropometric characteristics (height, weight, and BMI).

Results Data showed a significant age-associated improvement in ES for all 6 conditions $(p<0.05)$ and in CES $(p=0.001)$. For both genders, ( 1$)$ somatosensory function was adult-like by age 5 to 8 years, (2) visual function peaked around age 12 years, and (3) vestibular function reached maturity by age 15 to 17 years $(p<0.05)$. A moderate positive correlation $(r(140)=0.684, p=0.01$; two-tailed) between height and CES was found and a weak positive correlation $(r(140)=0.198, p=0.01)$ between height and somatosensory ratio was noted. Lower vestibular ratio scores were observed in children who had a higher BMI $(p=0.001)$.

Conclusion The efficient use of individual sensory system input to maintain balance does not occur at the same age. Age and gender affect the changes in sensory weighting strategies, while height and BMI influence postural control in children. These factors need to be accounted for in child assessment.

Postural control is defined as an individual's ability to achieve and maintain balance during a desired posture or activity. ${ }^{1}$ Factors contributing to postural control include (1) a sensory organization process whereby vision, vestibular, and somatosensory inputs are integrated by the central nervous system (CNS), (2) a motor adjustment process that requires coordination of musculoskeletal reflexes, and (3) an internal representation of positions of body parts in space. ${ }^{2}$ Together, these processes enable the body to respond to sensory inputs (somatosensory, visual, vestibular) with muscular output to maintain a specific static position (e.g., upright stance) or dynamic condition (e.g., walking), as well as compensate for body perturbations to prevent falls.

To coordinate forces required for maintaining or restoring balance in static and dynamic conditions, an individual must be able to organize sensory inputs. ${ }^{2}$ The somatosensory system relies primarily on proprioceptive and cutaneous input, through the extensor muscles and joint systems. It provides information about the orientation of body parts relative to the support surface and to one another. The visual system directs visual images to the CNS about the body's position in its surroundings. The peripheral vestibular system (semicircular canals and otolith organs) analyzes spatial orientation and also detects angular and linear velocity. ${ }^{3}$ Sensory organization involves processing these individual sensory cues through a hierarchical neural system including the vestibular nuclei, spinal cord, brainstem, cerebellum, basal ganglia, and cerebral cortex (parieto-insular vestibular cortex).,

The motor output includes two main reflexes: the vestibulo-ocular reflex (VOR) and vestibulospinal reflex (VSR). The VOR maintains gaze stability and preserves visual acuity during head movements. The VSR is accountable for postural control and utilizes otolithic inputs primarily driving the lateral vestibulospinal tract to generate compensatory movements in response to sudden or unexpected postural changes, to prevent falls. ${ }^{5}$ The VSR uses the medial vestibulospinal tract to activate motoneurons in the neck to coordinate the neck-eye movement, after receiving inputs primarily from semicircular canals. ${ }^{6}$ These reflexes allow for focusing the image on the fovea of the retina and for maintaining balance and equilibrium, with the brainstem integrating sensory information and the cerebellum coordinating and regulating posture, movement, and balance. Additionally, the prefrontal cortex and supplementary motor area have been shown to assist with interlimb coordination, postural adjustment for hand-foot coordination, gait, and postural control. ${ }^{4}$

The emerging motor effect of posture and balance has been described as a "weighted sum" of all sensory signals. ${ }^{7}$ Each sensory channel contributes a weight, then the weighted variables are summed to produce a response modulated according to the relevance of the incoming afferents. When a sensory signal is absent or weak, the CNS weighs heavily on the more reliable sensory inputs to produce appropriate postural behaviors. The effective utilization and reweighting of sensory system input for balance control have been shown to develop across the lifespan. ${ }^{8}$

From a physiological standpoint, the vestibular system is the first sensory system to develop at 49 days in utero. At birth, the semicircular canals and otolith organs are morphologically complete and the vestibular nerve is myelinated. ${ }^{9}$ The development of the visual system takes longer. Binocular vision is mature by age 4 to 5 months and stereoacuity by age 6 to 7 months; however, visual nerve myelination is not intact until the age of 2 years, and retinal development continues to at least the age of 4 years. ${ }^{10}$ Studies have shown that young children are more dependent (i.e., put more weight) on visual cues, even though the visual system is less mature than other sensory inputs for postural control. Lee and Aronson ${ }^{11}$ and Woollacott and Shumway-Cook ${ }^{12}$ reported dependence on visual input when a child is learning to stand and walk (18-36 months old). Forssberg and Nashner ${ }^{13}$ also suggested that the visual system was the dominant postural control system before 7.5 years of age. In line with these findings, Casselbrant and colleagues reported that children aged 4 to 8 years used vision more heavily than other sensory information for postural control. Although Sparto et $\mathrm{al}^{14}$ found that children aged 7 to 12 years 
and adults have a similar ability to use dynamic visual cues for postural control, they showed that children did not yet display adult-like integration and utilization of somatosensory cues to stabilize posture when visual cues were conflicting.

Vestibulospinal influences emerge at the age of 4 to 6 years but continue to mature until the age of 15 years. ${ }^{15,16}$ The resolution of somatosensory/visual conflict appears to be poor through the ages of 6 to 12 years because of differences in maturation rate among sensory systems. ${ }^{11,15-17}$

The sensory organization test (SOT), a subtest of computerized dynamic posturography (CDP), is a tool used clinically to assess postural control. The SOT protocol allows for an objective and quantitative analysis of sensory (i.e., vestibular, visual, and somatosensory) and motor components of balance. $^{18}$ The SOT can isolate and quantify the use of each sensory system and the adaptive (or maladaptive) responses of the CNS..$^{19}$ The SOT algorithm has been used to track the development and maturation pattern of equilibrium in children of different ages by delineating the contribution of the three sensory inputs (vestibular, visual, and somatosensory), and to determine how weighting strategy patterns change as maturation occurs throughout childhood.

Several researchers have evaluated the maturation of balance and sensory weighting strategies in large groups of children, using the SOT. ${ }^{15,20-25}$ Proprioceptive function seemed to mature early, with adult-like performance being reached by the age of 3 to 4 years. Visual and vestibular function required more time to mature, with adult-like performance not occurring until the age of 15 to 16 years. SOT results suggest that reliance on vestibular system input for postural stability appears to continue throughout late childhood and even adolescence. It remains unclear in the literature whether the SOT performance of children aged 16 to 18 years is adult-like or continues to improve.

Despite the relative maturity of sensory systems, differences in postural control and sensory weighting between children and adults may be attributed to neural integration or possibly anthropometric characteristics (height, weight, body mass index [BMI], etc.). ${ }^{23,26,27}$ The influence of anthropometric characteristics on postural control is also unclear and conflicting. For example, Investigators have reported that height, weight, and BMI did not affect postural sway. ${ }^{28,29}$ Peterson et $\mathrm{a}^{23}$ highlighted that anthropometric characteristics played only a small role in postural control. In contrast, Cumberworth et $\mathrm{al}^{26}$ found a correlation between visual ratio and height and McGraw et $\mathrm{al}^{27}$ found that obese children had a greater sway (compared to age-matched nonobese).

The purpose of this study was threefold: (1) to evaluate the development of postural control in a sample of healthy children aged 5 to 17 years old, (2) to analyze changes in sensory weighting pattern strategies as maturation occurs via the SOT, and (3) to determine the extent to which anthropometric characteristics (height, weight, and BMI) influence postural control during maturation. The results of this study will contribute to the understanding of sensory weighting strategies used by children for balance control as they mature and contribute to the body of SOT normative data collected for the pediatric population.

\section{Methodology}

This cross-sectional study was conducted over a period of 24 months at the Audiology and Balance Center, American University of Beirut Medical Center, after approval from the Institutional Board Review (AUB IRB \#: OTO.KS.05).

\section{Participants}

One hundred twenty children stratified over four age groups (5-8 years, $9-11$ years, $12-14$ years, and $15-17$ years) were included in this study. We followed the guidelines of the Centers for Disease Control and Prevention that specify developmental milestones in the following groups: preschoolers [3-5 years of age], middle childhood [6-8 years of age], middle childhood [9-11 years of age], young teens [12-14 years of age], and teenagers [15-17 years of age]. These divisions are related to the four main areas or channels in which children grow: physical, psychological, cognitive, social, emotional, as well as puberty and gender identity. ${ }^{30}$ Because 3- and 4-year-old children were often uncooperative for some of our tests [mainly caloric test], we merged the small group of 5-year-olds with the group of 6- to 8-yearolds). ${ }^{30}$ Each age group included 15 boys and 15 girls. Additionally, a control group of 20 healthy adults aged 20 to 25 years ( 10 females and 10 males) was considered as group 5. - Table 1 summarizes the participants' demographics and anthropometric characteristics (gender, age, height, weight, and BMI).

All participants were healthy, with no audiological, neurological, or vestibular pathologies. Prior to testing, the parents/guardians and participant provided written consent, granting approval to participate. A thorough case history was taken from each participant. Children were excluded from the study if the parents/guardian reported a history of otitis media, chronic ear infections, hearing loss, meningitis, previous ear surgery, concussion, poor vision (corrected visual acuity poorer than $20 / 40$ was not accepted), skeletal malformation, immune-deficiency disorders, cancer, or known disorders of metabolic, neurologic, or genetic origin.

An audiological evaluation was performed to ensure that both ears of participants had (1) normal otoscopic findings, (2) pure-tone air- and bone-conduction thresholds $\leq 15 \mathrm{~dB}$ hearing level $(\mathrm{HL})$ at all test frequencies $(0.25,0.5,1.0,2.0$, and $4.0 \mathrm{kHz}$ ), with air-bone gaps $\leq 10 \mathrm{~dB}$ HL (MADSEN Astera-2 audiometer; GN Otometrics, Copenhagen, Denmark), and (3) normal tympanograms (type A) with ipsilateral and contralateral acoustic reflexes present (acoustic reflex threshold $\leq$ $100 \mathrm{~dB}$ ) at $0.5,1.0$, and $2.0 \mathrm{kHz}$ (GSI TympStar Middle Ear Analyzer v.2; Grason Stadler VIASYS NeuroCare, WI). A neurological screening test was performed (finger-to-nose, rapid alternating movements, tandem walk, and Romberg's test); only participants who had normal findings of the neurological screening were included in the study. Oculomotor testing (saccade and smooth pursuit) and monothermal air caloric testing $\left(24^{\circ} \mathrm{C} ; 60\right.$-second irrigation) were completed using videonystagmography (VNG Ulmer device, Synapsys, Marseille, France). Only participants who had normal oculomotor findings and caloric results (asymmetry $\leq 15 \%$; total 
Table 1 Demographic and anthropometric characteristics (gender, age, height, weight, and body mass index) of healthy participants with no audiological, neurological, or vestibular pathologies

\begin{tabular}{|c|c|c|c|c|c|c|}
\hline \multicolumn{2}{|l|}{ Groups } & \multirow{2}{*}{$\begin{array}{l}n \\
15\end{array}$} & \multirow{2}{*}{$\begin{array}{l}\text { Age }(y) \\
\text { Mean } \pm \text { SD } \\
7 \pm 1 \\
\end{array}$} & \multirow{2}{*}{$\begin{array}{l}\text { Height }(\mathrm{cm}) \\
\text { Mean } \pm \text { SD } \\
121 \pm 17\end{array}$} & \multirow{2}{*}{$\begin{array}{l}\text { Weight (kg) } \\
\text { Mean } \pm \text { SD } \\
26 \pm 6\end{array}$} & \multirow{2}{*}{$\begin{array}{l}\text { Body mass index (BMI) } \\
\text { Mean } \pm \text { SD } \\
17.17 \pm 1.62\end{array}$} \\
\hline \multirow[t]{2}{*}{$5-8 y$} & Female & & & & & \\
\hline & Male & 15 & $7 \pm 1$ & $120 \pm 7$ & $23 \pm 4$ & $16.19 \pm 1.88$ \\
\hline \multirow[t]{2}{*}{$9-11 y$} & Female & 15 & $10 \pm 1$ & $142 \pm 8$ & $38 \pm 8$ & $18.81 \pm 2.96$ \\
\hline & Male & 15 & $9 \pm 1$ & $135 \pm 11$ & $32 \pm 7$ & $17.20 \pm 2.65$ \\
\hline \multirow[t]{2}{*}{$12-14 y$} & Female & 15 & $13 \pm 1$ & $159 \pm 6$ & $53 \pm 7$ & $20.66 \pm 1.84$ \\
\hline & Male & 15 & $13 \pm 1$ & $162 \pm 8$ & $56 \pm 10$ & $21.00 \pm 2.35$ \\
\hline \multirow[t]{2}{*}{$15-17 y$} & Female & 15 & $16 \pm 1$ & $161 \pm 5$ & $54 \pm 5$ & $20.77 \pm 1.67$ \\
\hline & Male & 15 & $16 \pm 1$ & $168 \pm 8$ & $64 \pm 10$ & $22.26 \pm 1.72$ \\
\hline \multirow[t]{2}{*}{$20-25$ y } & Female & 10 & $22 \pm 2$ & $162 \pm 5$ & $58 \pm 8$ & $22.56 \pm 3.06$ \\
\hline & Male & 10 & $22 \pm 2$ & $174 \pm 8$ & $75 \pm 9$ & $24.06 \pm 2.49$ \\
\hline
\end{tabular}

Abbreviation: SD, standard deviation.

reflectivity combining both sides $\geq 12^{\circ} / \mathrm{s}$ ) were included in the study. ${ }^{31}$ Children who were uncooperative during the screening tests were excluded.

\section{Sensory Organization Test}

Postural stability was tested using a SMART Equitest posturography system and standard SOT protocol (Natus NeuroCom International, Clackamas, OR). The Equitest consists of a dual platform capable of rotating in the anteroposterior direction, and a mechanically movable visual screen/surround that is also capable of rotating in the anteroposterior direction. The movable platform and screen are used to manipulate visual, vestibular, and somatosensory inputs during the SOT. The SOT protocol ( - Fig. 1) consists of three 20-second trials under six different sensory conditions in which the surface and/or visual surround are systematically manipulated: (1) eyes open, surround and platform stable, (2) eyes closed, surround and platform stable, (3) eyes open, sway-referenced surround, platform stable, (4) eyes open, sway-referenced platform, (5) eyes closed, sway-referenced platform, and (6) eyes open, swayreferenced surround and platform. The system quantifies the effect of these manipulations on postural stability by measuring the individual's spontaneous sway. The stimulus manipulations performed by the SOT force the individual to reweight another sensory input to maintain postural control. In particular, swayreferencing provides inaccurate sensory input to both the visual and somatosensory systems and allows the assessment of vestibular function and further evaluation of how the three sensory inputs are weighted by the individual. ${ }^{23,32}$

The composite equilibrium score (CES), equilibrium scores (ES), and sensory analysis ratios (SAS) were examined in this study. The CES measures the overall level of performance on the SOT and is a weighted average calculated from the mean performance of Conditions 1 and 2 and the average of all trials from Conditions 3 through $6 .{ }^{19}$ The ES for each condition trial is determined by comparing the angular difference between the individual's calculated maximum and minimum sagittal plane body sway to a theoretical maximum displacement $\left(12.5^{\circ}\right) .^{33}$ The result is expressed as an inverse percentage between 100 (no body sway) and 0 (fall).

$$
\text { Equilibrium }=12.5^{\circ}-\left(\theta_{\max }-\theta_{\min }\right) / 12.5^{\circ} \times 100
$$

The SAS represents the influence of each sensory system on the individual's stability and quantifies the relative difference in scores between two conditions. ${ }^{19}$ The somatosensory ratio compares Condition 2 to Condition 1 and assesses the ability of an individual to use somatosensory information

\begin{tabular}{|c|c|c|c|c|c|c|c|}
\hline 1 & 2 & 3 & 4 & 5 & 6 & Condition 1 & Using the somatosensory system mainly \\
\hline \multirow[t]{4}{*}{$\begin{array}{l}\text { Normal } \\
\text { vision }\end{array}$} & $\begin{array}{l}\text { Absent } \\
\text { vision }\end{array}$ & $\begin{array}{l}\text { Sway-referenced } \\
\text { vision }\end{array}$ & $\begin{array}{c}\text { Normal } \\
\text { vision }\end{array}$ & $\begin{array}{l}\text { Absent } \\
\text { vision }\end{array}$ & $\begin{array}{l}\text { Sway-referenced } \\
\text { vision }\end{array}$ & Condition 2 & $\begin{array}{l}\text { Absent vision and mainly using somatosensory } \\
\text { input }\end{array}$ \\
\hline & & & & & & Condition 3 & $\begin{array}{l}\text { Altered vision and mainly using somatosensory } \\
\text { input }\end{array}$ \\
\hline & & & & & & Condition 4 & $\begin{array}{l}\text { Altered proprioception and mainly using visual } \\
\text { input }\end{array}$ \\
\hline & & & & & & Condition 5 & $\begin{array}{l}\text { Altered proprioception and absent vision and } \\
\text { relying mainly on vestibular input }\end{array}$ \\
\hline \multicolumn{3}{|c|}{ Fixed support } & \multicolumn{3}{|c|}{ Sway-referenced support } & Condition 6 & $\begin{array}{l}\text { Altered proprioception and vision, relying mainly } \\
\text { on vestibular input }\end{array}$ \\
\hline
\end{tabular}

Fig. 1 The sensory organization test is designed to measure an individual's ability and to use individual sensory system input cues to maintain balance control, by methodically manipulating sensory input (e.g., by eliminating visual input or distorting somatosensory or visual information by sway-referencing the platform or visual surround) as seen in each of the 6 conditions. 
Table 2 Equations and significance of each SOT measurement parameter, including condition-specific equilibrium scores (ES1ES6), composite equilibrium score (CES), and sensory analysis scores (SAS: somatosensory ratio, visual ratio, vestibular ratio, visual preference ratio)

\begin{tabular}{|l|l|l|}
\hline Name & Equation & Significance \\
\hline $\begin{array}{l}\text { Equilibrium score } \\
\text { ES1-ES6) }\end{array}$ & $\begin{array}{l}\text { ES closer to 100\% indicating perfect } \\
\text { stability and 0\% indicating a fall. }\end{array}$ & $\begin{array}{l}\text { Comparing the angular difference between the subject's } \\
\text { maximum anterior to the posterior center of gravity dis- } \\
\text { placements to the theoretical maximum displacement and its } \\
\text { average between the 2 trials }\end{array}$ \\
\hline Composite score & $\begin{array}{l}=[\mathrm{ES} 1+\mathrm{ES} 2+3 \text { (ES3+ } \\
\text { ES4 }+ \text { ES5 }+ \text { ES6)] / 14 }\end{array}$ & $\begin{array}{l}\text { Global determination of normal versus abnormal } \\
\text { performance }\end{array}$ \\
\hline Somatosensory ratio & $=$ ES2 / ES1 & $\begin{array}{l}\text { Participant's ability to use input from the somatosensory } \\
\text { system to maintain balance (even when visual cues are } \\
\text { removed) }\end{array}$ \\
\hline Visual ratio & $=$ ES4 / ES1 & $\begin{array}{l}\text { Participant's ability to use input from the visual system to } \\
\text { maintain balance (even when somatosensory cues are } \\
\text { altered) }\end{array}$ \\
\hline Vestibular ratio & $=$ ES5 / ES1 & $\begin{array}{l}\text { Participant's ability to use input from the vestibular system to } \\
\text { maintain balance (even when visual cues are removed and } \\
\text { somatosensory are altered) }\end{array}$ \\
\hline Visual preference ratio & $=$ ES3 + ES6 / ES2 + ES5 & $\begin{array}{l}\text { Degree to which patient relies on visual information to } \\
\text { maintain balance (correct/incorrect information) }\end{array}$ \\
\hline
\end{tabular}

Abbreviation: SOT, sensory organization test.

Note: Table adapted from Balance Manager Systems Clinical Interpretation Guide Computerized Dynamic Posturography, NeuroCom International, Inc.

for maintaining balance. The visual ratio compares Condition 4 to Condition 1 and assesses the ability of an individual to use visual information for maintaining balance. The vestibular ratio compares Condition 5 to Condition 1 and assesses the ability of an individual to use a vestibular information for maintaining balance. Finally, the visual preference ratio compares Conditions 3 and 6 to Conditions 2 and 5 and assesses the degree to which an individual relies on visual information to maintain balance, even when the information is incorrect or misleading. - Table $\mathbf{2}$ summarizes the equations used to calculate these ratios.

\section{Procedure}

All subjects completed the six sensory conditions of the SOT (-Fig. 1). In each sensory condition, subjects were given two trials each of 20 seconds (the decision to perform two trials in each SOT condition was based on the findings of Rine et $\mathrm{al}^{16}$ who reported that the use of two trials resulted in good test-retest reliability scores. In our study, stability scores were reliable between the two trials on all 6 test conditions $[\alpha \mathrm{C} 1=0.92, \alpha \mathrm{C} 2=0.91, \alpha \mathrm{C} 3=0.90, \alpha \mathrm{C} 4=0.82$, $\alpha \mathrm{C} 5=0.74, \alpha \mathrm{C} 6=0.69]) .{ }^{16} \mathrm{~A}$ detailed explanation of each test or trial was provided before beginning the SOT condition. Short rest periods were provided when needed. The total test duration was 20 minutes.

Throughout the test, subjects stood on the platform, while wearing a safety harness that was attached overhead and designed to prevent falls but not limit sway. The examiner positioned the subjects' feet on the platform, making sure that the medial malleolus centered over a marking stripe that laterally transects the two force plates, and the ankle joints were aligned with the platform axis. Subjects were asked to maintain a quiet upright stance, avoid touching the walls or harness during testing, and keep their eyes closed when asked to do so (condition-dependent). An examiner remained stationed behind each subject for safety throughout the test.

\section{Data Analysis}

Forward regression analysis was used to find the best model between CES and SAS, the independent variables (age, gender), and anthropometric characteristics (height, weight, categorical BMI [the use of categorical BMI was considered appropriate because age, height, and weight are highly correlated among children. Initially, BMI was calculated by body weight [in kilograms] divided by height [in meters squared]. Then, subjects were categorized as "underweight," "normal," "overweight," or "obese." Knowing that adiposity varies with age and gender during childhood and adolescence, categorical BMI values took age and gender into consideration]). ${ }^{34,35}$ Additionally, two-way analysis of variance (ANOVA) was used to compare subgroups; post hoc Tukey (honest significant difference) tests were used to pinpoint statistically significant differences. Pearson's correlations were run to identify whether relationships existed between continuous variables (CES, SAS) and the categorical variables (age, gender). An $\alpha$ level of 0.05 was used for all statistical tests. All data analyses were completed using SPSS Version 25 (IBM Inc., Chicago, IL).

\section{Results}

Means and standard deviations for the CES, condition-specific ES, and SAS scores (somatosensory ratio, visual ratio, vestibular ratio, visual preference ratio) are summarized and 
Table 3 Normative posturography data collected in our sample group

\begin{tabular}{|c|c|c|c|c|c|c|c|c|c|c|c|c|}
\hline & & & \multicolumn{10}{|c|}{ Age groups } \\
\hline & & & \multicolumn{2}{|l|}{$5-8 y$} & \multicolumn{2}{|l|}{$9-11 y$} & \multicolumn{2}{|c|}{$12-14 y$} & \multicolumn{2}{|c|}{$15-17 y$} & \multicolumn{2}{|c|}{$20-25 y$} \\
\hline & & & ES & SD & ES & SD & ES & SD & ES & SD & ES & SD \\
\hline \multirow[t]{22}{*}{ Gender } & \multirow[t]{11}{*}{ Female } & Condition 1 (ES1) & 86.90 & 3.02 & 85.47 & 4.32 & 91.38 & 4.30 & 94.10 & 2.29 & 93.20 & 2.53 \\
\hline & & Condition 2 (ES2) & 83.13 & 3.46 & 82.53 & 6.05 & 90.11 & 4.19 & 92.10 & 2.67 & 90.70 & 2.62 \\
\hline & & Condition 3 (ES3) & 80.90 & 4.21 & 79.87 & 7.14 & 87.40 & 5.98 & 90.73 & 3.85 & 89.20 & 2.34 \\
\hline & & Condition 4 (ES4) & 59.23 & 7.60 & 62.13 & 12.44 & 75.93 & 9.30 & 78.87 & 10.75 & 82.40 & 3.16 \\
\hline & & Condition 5 (ES5) & 41.10 & 12.87 & 47.07 & 10.21 & 53.37 & 13.21 & 62.47 & 10.50 & 64.60 & 7.63 \\
\hline & & Condition 6 (ES6) & 44.80 & 14.47 & 53.73 & 12.69 & 53.50 & 9.38 & 64.90 & 10.06 & 66.90 & 7.37 \\
\hline & & Composite score (CES) & 60.58 & 6.06 & 64.03 & 7.39 & 70.86 & 6.00 & 76.94 & 6.81 & 78.00 & 3.83 \\
\hline & & Somatosensory ratio & 95.71 & 3.78 & 96.63 & 6.18 & 98.66 & 3.10 & 97.89 & 2.49 & 97.50 & 0.70 \\
\hline & & Visual ratio & 68.16 & 8.50 & 72.48 & 12.37 & 83.31 & 11.05 & 83.77 & 11.00 & 89.17 & 1.83 \\
\hline & & Vestibular ratio & 47.43 & 15.02 & 55.00 & 10.98 & 58.41 & 14.24 & 66.36 & 10.94 & 69.89 & 7.94 \\
\hline & & Visual preference ratio & 101.57 & 11.61 & 103.34 & 9.39 & 98.95 & 12.15 & 100.74 & 6.13 & 100.71 & 3.20 \\
\hline & \multirow[t]{11}{*}{ Male } & Condition 1 (ES1) & 77.98 & 10.52 & 83.77 & 5.13 & 90.63 & 3.29 & 88.67 & 3.23 & 94.30 & 3.49 \\
\hline & & Condition 2 (ES2) & 75.33 & 10.76 & 80.67 & 6.42 & 88.70 & 3.27 & 88.33 & 3.16 & 91.30 & 3.86 \\
\hline & & Condition 3 (ES3) & 73.67 & 9.87 & 81.53 & 6.83 & 87.57 & 4.50 & 85.60 & 5.11 & 89.60 & 3.65 \\
\hline & & Condition 4 (ES4) & 54.77 & 10.20 & 55.67 & 12.85 & 71.70 & 9.87 & 69.77 & 8.99 & 82.50 & 5.38 \\
\hline & & Condition 5 (ES5) & 42.00 & 11.70 & 41.96 & 14.77 & 55.00 & 13.45 & 56.97 & 12.85 & 67.10 & 9.37 \\
\hline & & Condition 6 (ES6) & 44.37 & 15.71 & 46.03 & 17.40 & 57.23 & 13.11 & 62.30 & 10.73 & 67.20 & 9.00 \\
\hline & & Composite score (CES) & 56.98 & 10.49 & 60.00 & 8.94 & 70.99 & 6.30 & 71.49 & 5.24 & 79.20 & 5.45 \\
\hline & & Somatosensory ratio & 96.59 & 5.02 & 96.26 & 3.94 & 97.91 & 3.03 & 99.68 & 3.35 & 96.90 & 2.28 \\
\hline & & Visual ratio & 70.12 & 7.83 & 66.46 & 14.00 & 78.97 & 9.54 & 78.71 & 10.06 & 86.69 & 3.86 \\
\hline & & Vestibular ratio & 52.99 & 10.15 & 49.79 & 16.12 & 60.69 & 14.56 & 64.31 & 14.53 & 70.46 & 8.92 \\
\hline & & Visual preference ratio & 100.66 & 9.21 & 105.05 & 13.23 & 101.04 & 7.62 & 102.27 & 8.87 & 98.90 & 2.85 \\
\hline
\end{tabular}

Note: Table summarizing the means and standard deviations (SDs) for condition-specific equilibrium scores for each of the 6 conditions (ES1-ES6), composite equilibrium scores (CES), and sensory analysis ratios (somatosensory, visual, vestibular and visual preference ratios), as a function of gender and age group.



Fig. 2 Composite equilibrium score (CES) and sensory analysis ratios as a function of age (*significant $p$-value). 
segregated by age group and gender in - Table 3. Additionally, CES and SAS are illustrated in - Fig. 2, as a function of age.

\section{Equilibrium Scores}

Regression analysis indicated the following:

- SOT Condition 1: ES was associated with age, gender, and weight $\left(\mathrm{ES} 1: R^{2}=0.464, F(3,136)=39.30, p=0.001\right)$. ES1 increased with age $(p=0.04)$ and was higher for females compared with males $(p=0.001)$. Moreover, as weight increased ES1 increased $\left(R^{2}\right.$ linear $\left.=0.352, p=0.001\right)$.

- SOT Conditions 2, 3, and 4: ES were affected by age, height, and gender $\left(\mathrm{ES} 2: R^{2}=0.469, F(3,136)=39.96, p=0.001\right.$; ES3: $\quad R^{2}=0.386, \quad F(3,136)=28.51, \quad p=0.001$; $\quad$ ES4: $\left.R^{2}=0.492, F(3,136)=43.874\right)$. In all three conditions,
ES increased with age (ES2: $p=0.014$, ES3: $p=0.008$, ES4: $p=0.001)$. Similarly, with increased height the ES increased $\left(\mathrm{ES} 2: R^{2}\right.$ linear $=0.386, p=0.001$; ES3: $R^{2}$ line$\mathrm{ar}=0.324, p=0.016$; ES4: $R^{2}$ linear $=0.388, p=0.017$ ). Finally, ES differed between males and females across age groups (ES2: $p=0.001$, ES3: $p=0.02$, ES4: $p=0.001$ ); females of all age groups tended to perform better than males.

- SOT Condition 5: ES increased as age increased (ES5: $\left.R^{2}=0.349, F(1,138)=73.85, p=0.001\right)$.

- SOT Condition 6: ES increased as a function of age $(p=0.003)$, height $\left(R^{2}\right.$ linear $\left.=0.298, p=0.001\right)$ and weight $\left(R^{2}\right.$ linear $\left.=0.224, p=0.013\right)\left(\mathrm{ES} 6: R^{2}=0.353, F\right.$ $(3,136)=24.78, p=0.0001)$.

Table 4 Multiple regression equations for composite equilibrium score (CES) and sensory analysis ratios

\begin{tabular}{|c|c|c|c|c|c|c|c|c|}
\hline \multicolumn{2}{|l|}{ Model } & & $B$ & $\begin{array}{l}\text { Standard } \\
\text { error }\end{array}$ & Beta & $t$ & Significance & $\begin{array}{l}\text { Partial } \\
\text { correlation }\end{array}$ \\
\hline \multirow[t]{6}{*}{ Composite score } & Constant & \multirow{6}{*}{$\begin{array}{l}R^{2}=0.561 \\
F(3,136)=57.881 \\
P=0.001\end{array}$} & 33.577 & 5.351 & & 6.274 & 0.000 & \\
\hline & Age & & 881 & 0.196 & 0.438 & 4.498 & 0.000 & 0.360 \\
\hline & Gender & & -2.846 & 1.149 & -0.142 & -2.477 & 0.014 & -0.208 \\
\hline & Height & & 0.166 & 0.048 & 0.336 & 3.445 & 0.001 & 0.283 \\
\hline & Weight & & & & & & & \\
\hline & BMI & & & & & & & \\
\hline \multirow{6}{*}{$\begin{array}{l}\text { Somatosensory } \\
\text { ratio }\end{array}$} & Constant & \multirow{6}{*}{$\begin{array}{l}R^{2}=0.0391 \\
F(1,138)=5.633 \\
p=0.019\end{array}$} & 91.829 & 2.363 & & 38.867 & 0.0000 & \\
\hline & Age & & & & & & & \\
\hline & Gender & & & & & & & \\
\hline & Height & & 0.037 & 0.016 & 0.198 & 2.373 & 0.0190 & 0.198 \\
\hline & Weight & & & & & & & \\
\hline & BMI & & & & & & & \\
\hline \multirow[t]{6}{*}{ Visual ratio } & Constant & \multirow{6}{*}{$\begin{array}{l}R^{2}=0.288 \\
F(1,138)=57.299 \\
p=0.001\end{array}$} & 60.169 & 2.395 & & 25.124 & 0.000 & \\
\hline & Age & & 1.315 & 0.174 & 0.542 & 7.570 & 0.000 & 0.542 \\
\hline & Gender & & & & & & & \\
\hline & Height & & & & & & & \\
\hline & Weight & & & & & & & \\
\hline & BMI & & & & & & & \\
\hline \multirow[t]{6}{*}{ Vestibular ratio } & Constant & \multirow{6}{*}{$\begin{array}{l}R^{2}=0.277 \\
F(2,137)=26.20 \\
p=0.001\end{array}$} & 46.316 & 4.008 & & 11.555 & 0.0000 & \\
\hline & Age & & 1.449 & 0.211 & 0.500 & 6.877 & 0.0000 & 0.507 \\
\hline & Gender & & & & & & & \\
\hline & Height & & & & & & & \\
\hline & Weight & & & & & & & \\
\hline & BMI & & -5.221 & 2.335 & -0.162 & -2.235 & 0.0270 & -0.187 \\
\hline \multirow{6}{*}{$\begin{array}{l}\text { Visual preference } \\
\text { ratio }\end{array}$} & Constant & \multirow{6}{*}{$\begin{array}{l}R^{2}=0.043 \\
F(3,136)=2.069 \\
p=0.109\end{array}$} & 77.235 & 12.737 & & 6.064 & 0.000 & \\
\hline & Age & & & & & & & \\
\hline & Gender & & & & & & & \\
\hline & Height & & & & & & & \\
\hline & Weight & & & & & & & \\
\hline & BMI & & & & & & & \\
\hline
\end{tabular}



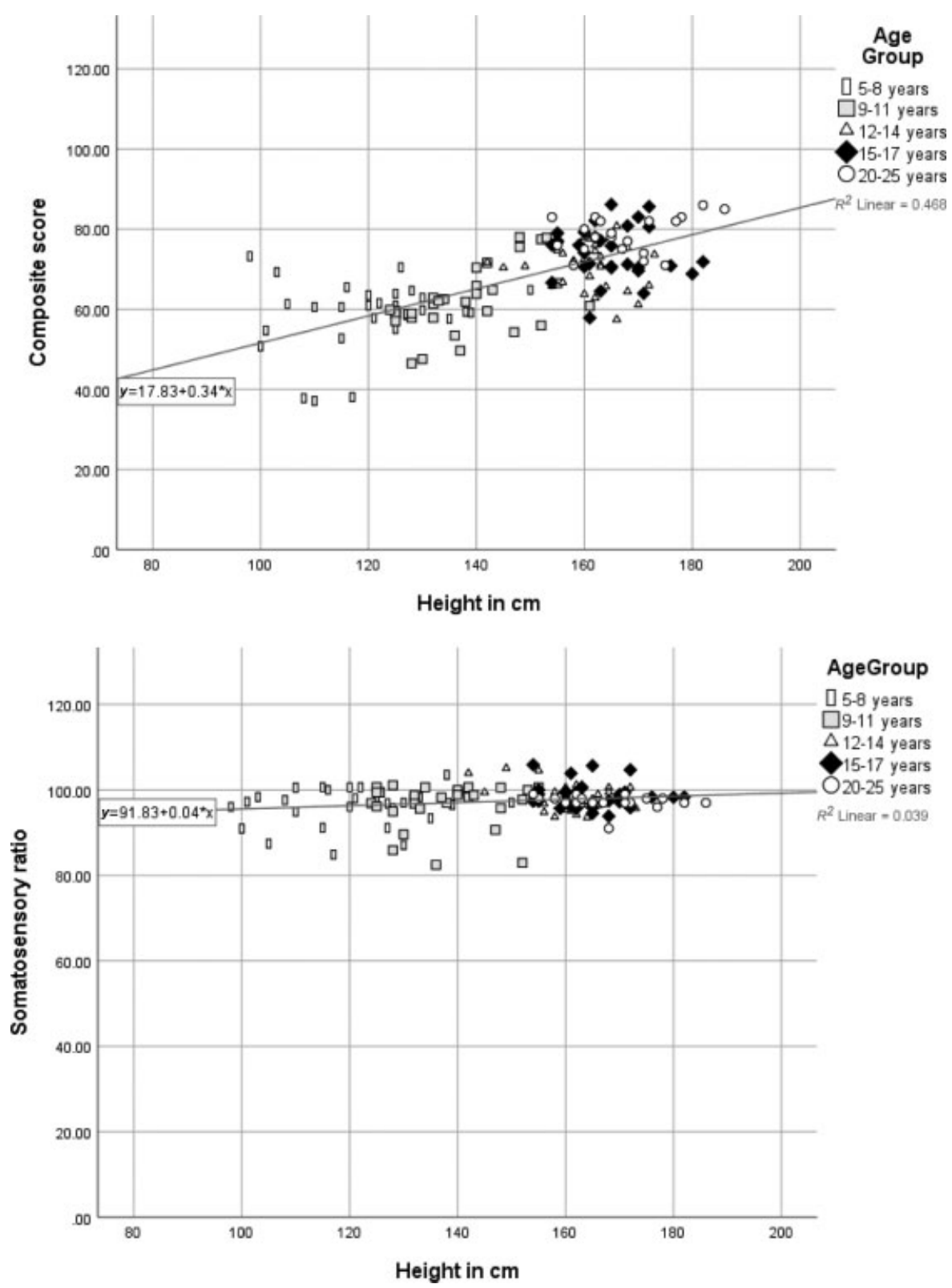

Fig. 3 Linear regression models demonstrated that composite equilibrium score (CES) increased with height (upper panel), similarly a correlation was seen between height and somatosensory ratio (lower panel).

\section{Composite Equilibrium Score}

Regression analysis ( - Table 4 ) demonstrated that age, gender, and height were predictors of the CES $\left(R^{2}=0.561, F(3\right.$, $136)=57.881, p=0.001$ ). As shown in - Fig. 2 , the mean CES for children aged 5 to 8 years was not different from those aged 9 to 11 years $(p=0.40)$; however, both groups scored lower than older children and adults $(p=0.001)$. The mean CES of children aged 12 to 14 years was similar to children aged 15 to 17 years $(p=0.387)$ but lower than adults $(p=0.003)$. The scores of adolescents (aged 15-17 years) did not differ significantly from those of adults. Gender had an effect only on the CES of children aged 15 to 17 years $(p=0.004)$, where females scored better than males. Results of the Pearson's correlation ( - Fig. 3; upper panel) indicated a significant positive association, of moderate strength, between height and CES $(r(140)=0.684, p=0.01$; two-tailed).

\section{Somatosensory Ratio}

Regression analysis indicated that the somatosensory ratio was influenced only by height $\left(R^{2}=0.0391, F(1,138)=5.633\right.$, $p=0.019)$; however, the correlation was weak $(r(140)=0.198$, $p=0.01$ ) (see - Fig. 3 ; lower panel). No significant differences in mean somatosensory ratios were found across age or gender. Across age groups, mean somatosensory scores were consistently high, ranging from 95.70 to 98.66 in females and 96.22 to 99.68 in males (-Table 2 ).

Mean somatosensory scores were consistently high, ranging from 95.70 to 98.66 in females and 96.22 to 99.68 in males, across age groups ( - Table $\mathbf{3}$ ).

\section{Visual Ratio}

Regression analysis demonstrated increasing visual ratio scores with age $\left(R^{2}=0.288, F(1,138)=57.299, p=0.001\right)$. 

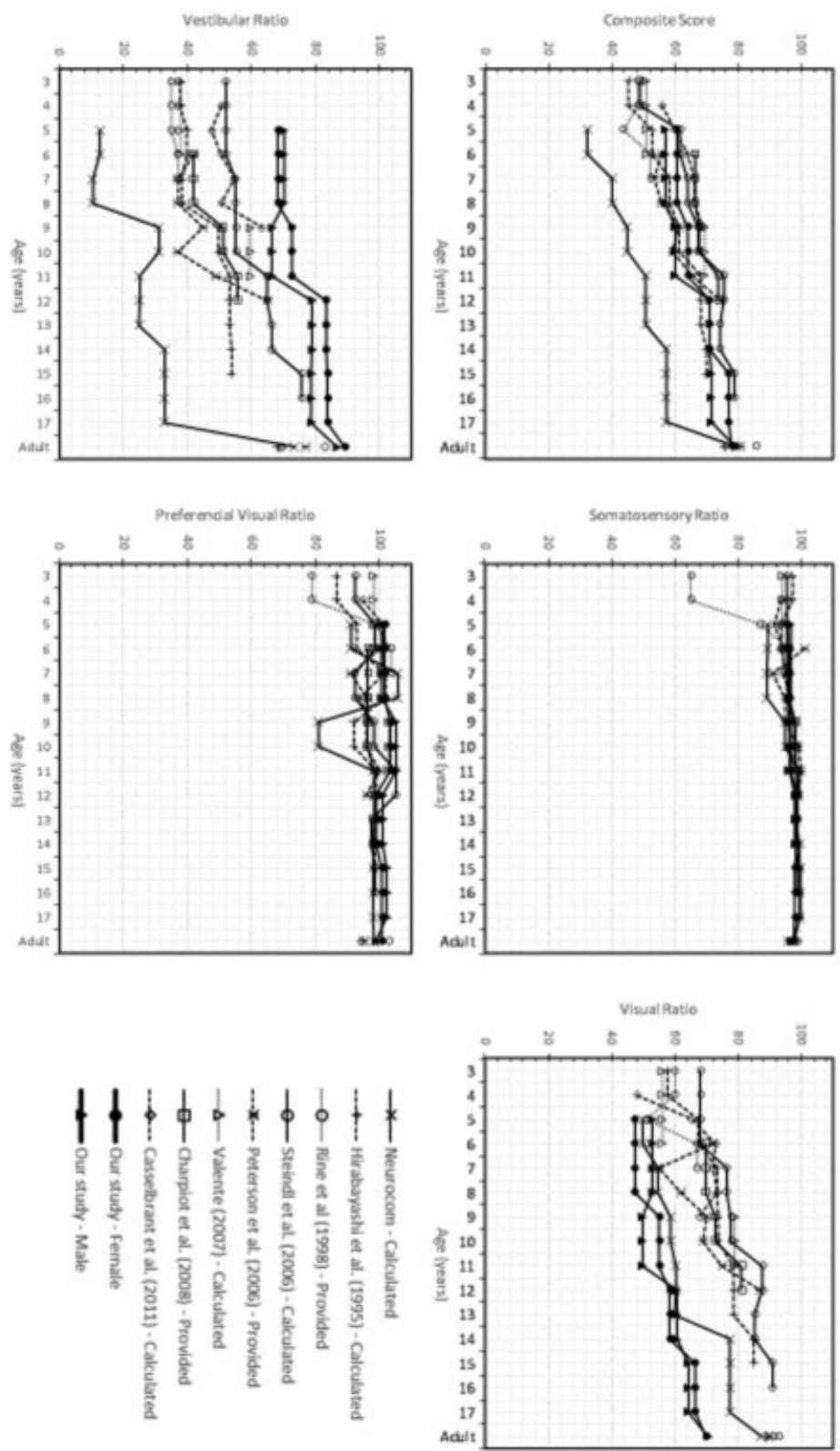

Fig. 4 Comparison of composite equilibrium scores (CES, panel A) and sensory analysis ratios (somatosensory in panel B, visual in panel C, vestibular in panel $\mathrm{D}$, visual preference in panel $\mathrm{E}$ ) in function of age, across studies using similar equipment to measure postural control.

A comparison of scores across age groups indicated a statistically significant difference in the performance of younger children (aged 5-11 years) versus older children (aged 12-17 years) or adults (-Fig. 2); performance of children between the ages of 12 and 17 years was not statistically different from adults.

\section{Vestibular Ratio}

Regression analysis showed that the mean vestibular ratio score increased with age $\left(R^{2}=0.277, F(2,137)=26.20\right.$, $p=0.001)$. As shown in - Fig. 2, the youngest groups of children (aged 5-8 and 9-11 years) performed similarly; however, their scores were significantly lower than the groups of older children (aged 12-14 and 15-17 years) and adults (respectively, $p=0.04,0.001$, and 0.0001 ). Scores of children aged 9 to 11 and 12 to 14 years were not signifi- cantly different $(p=0.20)$. Vestibular ratio scores of children aged 12 to 14 years were similar to children aged 15 to 17 years $(p=0.40)$ but significantly lower than adults $(p=0.03)$. Scores of adolescents (aged 15-17 years) were not significantly different from adults.

BMI category influenced the vestibular ratio $\left(R^{2}=0.253\right.$, $F=24.59, \quad p=0.001)$ but gender and height did not (-Table 4). In total, $83 \%$ of children had a normal BMI $(N=116), 14 \%$ were categorized as overweight $(N=20)$, $2.5 \%$ were considered obese $(N=3)$, and 1 child $(0.8 \%)$ was categorized as underweight (the BMI subcategory "underweight" had only 1 child [ $N=1]$; therefore, it was subsequently removed from the ANOVA). BMI category analysis showed that young children with a higher BMI had lower scores than children with a normal BMI in the same age group $(p=0.001)$. Specifically, children aged 5 to 8 years with 
a normal BMI had a mean vestibular ratio score of 51.14 compared with 45.64 in overweight children and 46.99 in obese children. A similar observation was noted in children aged 9 to 11 years; a mean vestibular ratio score of 53.71 was found in children with a normal BMI compared with 34.12 in obese children.

\section{Visual Preference Ratio}

No significant differences in mean visual preference ratio scores were found across age groups $(p=0.403)$ or gender $(p=0.661)$. Mean scores were high, ranging from 98.95 to 103.30 in females and 98.90 to 105.00 in males, across age groups ( - Table $\mathbf{3}$ ).

\section{Discussion}

\section{Age Effect}

\section{Composite Equilibrium Score}

Significant age-associated increases in overall performance on the SOT were found in this study, with children not achieving adult-like CES until age 15 to 17 years. In - Fig. 4A, mean CES of males and females are plotted alongside CES results reported in previous studies, which measured postural control with the Equitest and standard SOT protocol. Similar to the present study, Hirabayashi and Iwasaki ${ }^{15}$ found that CES increased with age; postural stability remained significantly lower than adults even in their oldest group of children (aged 15 years). Steindl et $\mathrm{al}^{24}$ reported a statistically significant difference in the CES of children aged 13 to 14 years compared with those aged 15 to 16 years, but not between 15 to 16 years olds and adults. Thus, they concluded that maturation was achieved around the age of 15 to 16 years. In a recent multicenter study, Goulème et $\mathrm{al}^{8}$ found that the maturation process of postural control was not yet achieved by age 16 years and may require further development. With the exception of the NeuroCom data (it is unclear why the NeuroCom CESs deviate significantly from the other studies. It is possible that factors such as anthropometric data are reflective of the population studied [diverse American population]), ${ }^{36}$ - Fig. 4A shows that mean CESs are relatively consistent as a function of age across studies, with only a small amount of variability observed.

\section{Somatosensory Ratio}

In our study, children in the youngest group (aged 5-8 years) utilized somatosensory information for postural control comparable to adults. - Fig. 4B shows reasonable agreement in somatosensory function across these studies. Other studies have reported that the maturity of somatosensory function in postural control emerges between 2 and 4 years of age. $^{12}$ These rapid increase and maturation of the sensorimotor control system suggest that the proprioceptive system seems to mature by age 3 to 4 years and reach adult levels of somatosensory function. ${ }^{15,24,26}$ Rine et al $^{16}$ found increased variability of somatosensory ratio scores in young children (aged 3-4 years) and suggested that a transition to a mature response in postural control is occurring in children between the ages of 3 and 7.5 years. In summary, the vast majority of researchers agree that somatosensory maturation happens at an early age and is complete by the age of 5 years, with minimal variability seen across childhood and adolescence.

\section{Visual Ratio}

The maturation pattern of visual function is not the same across studies using similar equipment to measure postural control ( - Fig. 4C). In our study, the visual ratio data suggested a possible maturation peak around the age of 12 to 14 years. Hirabayashi and Iwasaki ${ }^{15}$ concluded that the visual system continues to develop until reaching adult-like acuity by the age of 15 years. However, they observed that the visual ratio peaked twice: once at 5 to 6 years old and again at 11 to 13 years old. When comparing adults and children aged 7 to 12 years, Sparto et $\mathrm{al}^{14}$ found that both groups had similar abilities to use dynamic visual cues for postural control. - Fig. 4C reveals more variability in visual performance compared with somatosensory performance across studies. Mean somatosensory scores varied by as little as 13 (range: 56-69) in groups of 3 years old, to as much as 38 (range: $50-88$ ) in groups of 11 years old. This variability may be associated with age-height relations across different samples.

\section{Vestibular Ratio}

In the present study, vestibular function developed with age, reaching maturity by age 15 to 17 years. -Fig. 4D shows that vestibular system maturation is not consistent across studies. Peterson et $\mathrm{al}^{23}$ proposed that adult-like vestibular function is seen by the age of 12 years. Hirabayashi and Iwasaki ${ }^{15}$ reported nonlinear vestibular system maturation throughout childhood; they noted a sharp improvement in vestibular performance in children between the ages of 7 to 8 years and those aged 9 to 10 years. However, vestibular function continued to improve and was not fully mature in children aged 14 to 15 years (the oldest age group tested). Other researchers report vestibular system maturation continuing throughout childhood, with adult-like performance obtained around the age of 10 to 14 years. ${ }^{9,37}$ Similarly, Cumberworth et $\mathrm{al}^{26}$ observed that vestibular function was not yet mature by the age of 15 years. Excluding the data provided by NeuroCom, - Fig. 4D shows mean vestibular ratios varying across studies by as little as 17 (range: $35-52$ ) in groups of 3 years old, to as much as 30 (range: 53-83) in groups of children aged 14 to 17 years.

It is well established in the literature that the vestibular system is the first system to develop and is morphologically complete at birth, ${ }^{9}$ and can show mature responses as early as 6 months of age when evaluated via saccade and pursuit testing. ${ }^{26}$ A normal VOR response to low frequency can be observed via caloric testing, which assesses the horizontal semicircular canals and afferent inputs. ${ }^{38}$ Normal responses to high-frequency stimuli can be seen by the age of 6 months, using cervical and ocular vestibular-evoked myogenic potentials (cVEMP and oVEMP), which assess the integrity of the saccule and inferior nerve, and the utricle and superior nerve, respectively. ${ }^{39}$ However, the context-dependent 
reweighting of support surface (somatosensory), vestibular, and visual inputs are very complex and organizationally separate processes; this hierarchically higher process takes some time to mature. ${ }^{13}$ Higher processing ability is reflected in the SOT vestibular ratio, which is a value that reflects the maturation of these processes.

\section{Visual Preference Ratio}

The visual preference ratio indicated that all children were influenced by inaccurate visual input to a similar degree. A comparison across similar studies ( $\mathbf{F i g}$. 4E) indicates a small amount of variability in visual preference ratio in children under the age of 13 years; this was especially true for children aged 3 to 4 and 9 to 10 years. Mean visual preference ratios varied by as little as 4 (range: $98-102$ ) in children aged 13 to 17 years, to as much as 19 (range: 79-98) in children aged 3 to 4 years and 24 (range: 81-105) in children aged 9 to 10 years old.

\section{Sensory Integration}

Although the anatomical structures involved in sensory integration are detectable and mature early in life, it appears that a separate process of sensory maturation is required before the higher-level adaptive process of integration can occur. $^{12,13,16,24}$ The present study has shown that somatosensory function is mature as early as 5 to 8 years old, visual function peaks at around 12 years old, and vestibular function shows maturation around 15 to 17 years old. It is hypothesized that the predominance of one sensory system may be a strategy adopted by the CNS to avoid information conflict, and this strategy varies with age. Peterka ${ }^{7}$ showed that when adults stood on a firm surface with available visual input, sensory contributions consist of $70 \%$ somatosensory input, 20\% vestibular input, and 10\% visual input. However, when somatosensory accuracy was reduced through support surface oscillations, sensory recalibration changed the relative contributions to $70 \%$ vestibular, $20 \%$ visual, and $10 \%$ somatosensory to maintain postural stability.

The seminal work of Shumway-Cook and Woollacott ${ }^{40}$ demonstrated that adult-like postural control and sensory integration occurred in children aged 7 to 10 years. The findings of the study served as a basis for assessing postural development in children for many years. ${ }^{40}$ It was not until later that other studies reported on mature responses appearing much later in childhood or adolescence. ${ }^{15,23,41}$ Results of the current study support late postural control maturation, with sensory systems appearing to develop at different rates. Younger children mainly rely on visual information to maintain balance regardless of its accuracy and, as they mature, they change strategy to resemble that of adults. ${ }^{15}$ Charpiot et $\mathrm{al}^{21}$ examined performance on CDP in healthy children ranging in age from 3 to 6 years. The results indicated that balance control changed from being primarily visual-vestibular dependent at age 3 years to being somatosensory-vestibular dependent by age 6 years. However, the transition to adultlike use of information from all sensory conditions was not completed by age 6 years. Another study found that, when visual and somatosensory cues were conflicting, even older children (aged 7-12 years) were not as proficient at utilizing somatosensory cues for posture stabilization as were adults. ${ }^{14}$ "Nonmonotonic" development of postural control is characterized by a linear improvement of the use of visual inputs and/or of the reweighting process of visual/somatosensory inputs from 7 to 10 years of age, and after that, it improves at a steady rate until adulthood. 2,41

\section{Gender}

In this study, girls performed better than boys in children aged 5 to 8 years for SOT Conditions 1 to 4 . Notably, boys showed greater within-group variability than girls across age groups. Overall, the CES increased with age, with girls appearing to mature earlier than boys. Gender effects on posture stability have been studied extensively in the literature. Smith et $\mathrm{al}^{42}$ noted that girls aged 8 to 12 years had better postural stability and were more capable of integrating sensory inputs. However, boys were more affected by altered sensory input information, treated each sensory input separately, and relied more on somatosensory feedback. ${ }^{42}$ Similarly, Goulème et $\mathrm{al}^{8}$ found that the maturation process was linked with gender. In our study, the somatosensory, visual, and vestibular ratios were the same across gender. However, prior research showed a difference in gender and visual maturation even at the age of 15 to 16 years. ${ }^{24}$ Hirabayashi and Iwasaki ${ }^{15}$ noted a gender difference especially in females aged 7 to 8 years; where girls performed better than boys on Condition 5, suggesting that girls make better use of the vestibular cues.

\section{Height Effect}

The results of this study indicate that maturation of postural control correlates with increased height. A positive correlation between height and age has been previously established $^{43}$; hence, any independence of age associations between height and CES might be weak or absent. Girls and boys of the same age do not necessarily have the same height. Additionally, it is well established that children of different races grow to different heights. ${ }^{44}$ Height was shown to influence SOT results in this study. One way to control for this confound would be to factor in subjects' ethnicity. It may be that differences in height (and perhaps musculoskeletal development) in children of a given age but of different ethnic backgrounds could factor in (i.e., 12-year-olds of different ethnicities may have different body habitus). Population differences are believed to be related not only to genetic factors but also to environmental factors. ${ }^{45}$ In the present study, control for size differences was attempted using gender, height, weight, and BMI only.

\section{BMI Effect}

Vestibular function was affected by BMI in our study. There are two possible theories to be considered: (1) BMI varies with age and gender; accordingly, BMI may influence vestibular function. The effects may be related to age-dependent changes. BMI effects may also be ethnicity dependent, knowing that BMI levels differ considerably by ethnicity, and can vary among subpopulations within an ethnic group 
because of environmental and lifestyle factors. ${ }^{44}$ (2) Body composition may influence base support, foot posture alignment, and overall body/core stability ${ }^{46}$ A recent study has shown that anthropometric indicators interfered with children's postural balance. ${ }^{47}$ Consequently, BMI should be considered during CDP testing, especially with the increased prevalence of childhood obesity.

\section{Physical Activities and Sports Effect}

Previous studies have shown that SOT performance can be influenced by an individual's balance training (e.g., highly trained world-class athletes, ${ }^{48}$ circus performers, ${ }^{49}$ or military personnel ${ }^{50}$ ) and might differ from SOT performance in the general population. ${ }^{49}$ Children who are frequently involved in sports have better muscle strength and postural control. ${ }^{16,23,51}$ Moreover, the type of activity may show different sensory weighting. For example, performing sports such as judo results in more weight on proprioception, whereas performing ballet relies more on visual input. ${ }^{52}$ The effect of training was not taken into consideration in this study, as none of our subjects fell into any of these categories.

\section{Limitations}

Variability is seen mainly in the SOT visual ratio and vestibular ratio across studies using similar equipment to measure postural control (-Fig. 4). In these studies, some of the variability may have resulted from uncontrolled parameters, such as gender, height, and BMI. The sample size and testing protocol differences may also have played a role. Ethnicity and environmental factors (i.e., nutritional, psycho-social, socioeconomical $)^{44}$ may also have influenced the findings. Additional factors that may account for the variability observed include the extent of sports practice and also attention capacity during the assessment, ${ }^{20}$ which could affect the overall SOT performance. Another limitation of the present study was that not all parts of the vestibular system were assessed individually (mainly vertical canals, the saccule, and inferior vestibular nerve). This could have been performed by assessing all subjects by video head impulse test and VEMPs. Mallinson et $\mathrm{al}^{53}$ showed that CDP assessment does not correlate with oVEMP and cVEMP results. However, Jacobson et $\mathrm{al}^{54}$ showed that patients with abnormal unilateral saccular or inferior vestibular nerve function (i.e., abnormal cVEMP) demonstrated significantly impaired postural control. Although the relationship between CDP and VEMP is not clear, the authors acknowledge that the inclusion of VEMP testing would have provided further evidence of vestibular status. ${ }^{53,54}$ If undetected vertical canal or otolithic disorders were present in children, this could potentially have affected the findings of the study. Finally, little information is available in the literature about postural control changes in individuals transitioning to adulthood (i.e., ages 17-20). The above limitations should be considered and further investigated in future research.

\section{Conclusion and Clinical Applications}

The findings of the present study confirm that postural control strategies in children change throughout maturation.
The ability to utilize specific sensory inputs for balance maintenance evolves at different ages. Strategy choice (reweighting of sensory use) develops in synchrony with a child's postural control maturation and musculoskeletal growth. Finally, factors such as age, gender, weight, height, and BMI must be taken into consideration when applying normative data in a clinical setting.

In the clinical setting, it is important to utilize valid normative data when assessing a child with neuro-otological complaints. Thus, the following factors must be taken into consideration:

Age: the ability to utilize specific sensory inputs effectively develops at different ages. Findings of the present study indicated that somatosensory function is nearly mature by the age of 5 years, visual contribution reaches adult levels around 11 to 12 years old, and vestibular function continues to mature at least through the age of 15 to 17 years.

Gender: better postural control observed in females than in males is likely related to morphological and behavioral differences in growth maturation.

Anthropometric traits (height, weight, and BMI): postural sway may be influenced in subjects who fall outside normative values of anthropometric traits. The effects of this are unclear and further investigation is required.

Rehabilitation goals and outcomes: when reviewing the sensory weighting analysis, changes in postural responses with age need to be taken into consideration when planning rehabilitation for children and evaluating treatment outcomes.

\section{Presentation}

Data relevant to this research paper were presented as a poster titled "Normative data of Sensory Organization Test in children between 9 and 17 years old" during the 30th American Academy of Audiology Annual Conference, in Nashville, Tennessee (April 20, 2018).

\section{Conflict of Interest \\ None declared.}

\section{Acknowledgments}

We are grateful for the support of Dr. Georges Zaytoun, Dr. Marc Bassim, and the audiology team at the Department of Otorhinolaryngology-Head and Neck Surgery, American University of Beirut Medical Center. Moreover, we would like to thank students of the Medical Audiology Sciences Program, American University of Beirut, for their tremendous assistance in the initial screening of children, including Ms. Tamara Accaoui, Ms. Dana Cherri, Ms. Nour El Hidek, Ms. Jana Zgheib, Ms. Nour Thini, and Ms. Sima Abdul Jawad.

\section{References}

1 Pollock AS, Durward BR, Rowe PJ, Paul JP. What is balance? Clin Rehabil 2000;14(04):402-406

2 Cuisinier R, Olivier I, Vaugoyeau M, Nougier V, Assaiante C. Reweighting of sensory inputs to control quiet standing in children from 7 to 11 and in adults. PLoS One 2011;6(05):e19697 
3 Khan S, Chang R. Anatomy of the vestibular system: a review. NeuroRehabilitation 2013;32(03):437-443

4 Fujimoto H, Mihara M, Hattori N, et al. Cortical changes underlying balance recovery in patients with hemiplegic stroke. Neuroimage 2014;85(Pt 1):547-554

5 Morningstar MW, Pettibon BR, Schlappi H, Schlappi M, Ireland TV. Reflex control of the spine and posture: a review of the literature from a chiropractic perspective. Chiropr Osteopat 2005;13(16):16

6 Purves D, Augustine G, Fitzpatrick D, et al. Central Vestibular Pathways: Eye, Head, and Body Reflexes. In: Neuroscience, 2nd ed. Sunderland, MA: Sinauer Associates; 2001

7 Peterka RJ. Sensorimotor integration in human postural control. J Neurophysiol 2002;88(03):1097-1118

8 Goulème N, Debue $M$, Spruyt $K$, et al. Changes of spatial and temporal characteristics of dynamic postural control in children with typical neurodevelopment with age: results of a multicenter pediatric study. Int J Pediatr Otorhinolaryngol 2018;113:272-280

9 Nandi R, Luxon LM. Development and assessment of the vestibular system. Int J Audiol 2008;47(09):566-577

10 Brecelj J. From immature to mature pattern ERG and VEP. Doc Ophthalmol 2003;107(03):215-224

11 Lee DN, Aronson E. Visual proprioceptive control of standing in human infants. Percept Psychophys 1974;15(03):3529-3532

12 Woollacott MH, Shumway-Cook A. Changes in posture control across the life span-a systems approach. Phys Ther 1990;70(12): 799-807

13 Forssberg H, Nashner LM. Ontogenetic development of postural control in man: adaptation to altered support and visual conditions during stance. J Neurosci 1982;2(05):545-552

14 Sparto PJ, Redfern MS, Jasko JG, Casselbrant ML, Mandel EM, Furman JM. The influence of dynamic visual cues for postural control in children aged 7-12 years. Exp Brain Res 2006;168(04): 505-516

15 Hirabayashi S, Iwasaki Y. Developmental perspective of sensory organization on postural control. Brain Dev 1995;17(02): 111-113

16 Rine R, Rubish K, Feeney C. Measurement of sensory system effectiveness and maturational changes in postural control in young children. Pediatr Phys Ther 1998;10(01):16-22

17 Nashner LM, Shupert CL, Horak FB, Black FO. Organization of posture controls: an analysis of sensory and mechanical constraints. Prog Brain Res 1989;80(411):411-418, discussion 395-397

18 Kingma H, Gauchard GC, de Waele C, et al. Stocktaking on the development of posturography for clinical use. J Vestib Res 2011; 21(03):117-125

19 Nashner LM. Computerized dynamic posturography. In: Jacobson GP, Newman CW, Kartush JM, ed. Handbook of Balance Function Testing. San Diego: Singular Publishing Group; 1993:280-334

20 Casselbrant ML, Mandel EM, Sparto PJ, et al. Longitudinal posturography and rotational testing in children three to nine years of age: normative data. Otolaryngol Head Neck Surg 2010;142(05): 708-714

21 Charpiot A, Tringali S, Ionescu E, Vital-Durand F, Ferber-Viart C. Vestibulo-ocular reflex and balance maturation in healthy children aged from six to twelve years. Audiol Neurotol 2010;15(04): 203-210

22 Ferber-Viart C, Ionescu E, Morlet T, Froehlich P, Dubreuil C. Balance in healthy individuals assessed with Equitest: maturation and normative data for children and young adults. Int J Pediatr Otorhinolaryngol 2007;71(07):1041-1046

23 Peterson ML, Christou E, Rosengren KS. Children achieve adultlike sensory integration during stance at 12-years-old. Gait Posture 2006;23(04):455-463

24 Steindl R, Kunz K, Schrott-Fischer A, Scholtz AW. Effect of age and sex on maturation of sensory systems and balance control. Dev Med Child Neurol 2006;48(06):477-482
25 Valente M. Maturational effects of the vestibular system: a study of rotary chair, computerized dynamic posturography, and vestibular evoked myogenic potentials with children. J Am Acad Audiol 2007;18(06):461-481

26 Cumberworth VL, Patel NN, Rogers W, Kenyon GS. The maturation of balance in children. J Laryngol Otol 2007;121(05):449-454

27 McGraw B, McClenaghan BA, Williams HG, Dickerson J, Ward DS. Gait and postural stability in obese and nonobese prepubertal boys. Arch Phys Med Rehabil 2000;81(04):484-489

28 Goulding A, Jones IE, Taylor RW, Piggot JM, Taylor D. Dynamic and static tests of balance and postural sway in boys: effects of previous wrist bone fractures and high adiposity. Gait Posture 2003;17(02):136-141

29 Lebiedowska MK, Syczewska M. Invariant sway properties in children. Gait Posture 2000;12(03):200-204

30 Centers for Disease Control and Prevention. Child Development. 2019. Available at: https://www.cdc.gov/ncbddd/ childdevelopment/positiveparenting/index.html. Accessed August 31, 2020

31 Sinno S, Najem F, Smith Abouchacra K, Perrin P, Dumas G. Normative values of saccades and smooth pursuit in children aged 5 to 17 years. J Am Acad Audiol 2020;31(06):384-392

32 Trueblood PR, Rivera M, Lopez C, Bentley C, Wubenhorst N. Agebased normative data for a computerized dynamic posturography system that uses a virtual visual surround environment. Acta Otolaryngol 2018;138(07):597-602

33 Whipple R, Wolfson L, Derby C, Singh D, Tobin J. Altered sensory function and balance in older persons. J Gerontol 1993;48(Spec No):71-76

34 Keys A, Fidanza F, Karvonen MJ, Kimura N, Taylor HL. Indices of relative weight and obesity. J Chronic Dis 1972;25(06):329-343

35 Daniels SR, Khoury PR, Morrison JA. The utility of body mass index as a measure of body fatness in children and adolescents: differences by race and gender. Pediatrics 1997;99(06):804-807

36 NeuroCom International. I. Balance Manager Systems Clinical Interpretation Guide: Computerized Dynamic Posturography. Clackamas, OR: NeuroCom International, Inc.; 2008

37 Ornitz EM. Normal and pathological maturation of vestibular function in the human child. In: Romand R, ed. Development of Auditory and Vestibular Systems. Cambridge, MA: Academic Press; 1983:479-536

38 Eviatar L, Eviatar A. The normal nystagmic response of infants to caloric and perrotatory stimulation. Laryngoscope 1979;89(7 Pt 1):1036-1045

39 Jacot E, Van Den Abbeele T, Debre HR, Wiener-Vacher SR. Vestibular impairments pre- and post-cochlear implant in children. Int J Pediatr Otorhinolaryngol 2009;73(02):209-217

40 Shumway-Cook A, Woollacott MH. The growth of stability: postural control from a development perspective. J Mot Behav 1985; 17(02):131-147

41 Peterka RJ, Black FO. Age-related changes in human posture control: sensory organization tests. J Vestib Res 1990-19911 (01):73-85

42 Smith AW, Ulmer FF, Wong P. Gender differences in postural stability among children. J Hum Kinet 2012;33:25-32

43 de Onis M, Onyango AW, Borghi E, Siyam A, Nishida C, Siekmann J. Development of a WHO growth reference for school-aged children and adolescents. Bull World Health Organ 2007;85(09): 660-667

44 WHO Expert Consultation. Appropriate body-mass index for Asian populations and its implications for policy and intervention strategies. Lancet 2004;363(9403):157-163

45 Bentham J, Di Cesare M, Stevens GA, et al; NCD Risk Factor Collaboration (NCD-RisC). A century of trends in adult human height. eLife 2016;5:e13410

46 AlAbdulwahab SS, Kachanathu SJ. Effects of body mass index on foot posture alignment and core stability in a healthy adult population. J Exerc Rehabil 2016;12(03):182-187 
47 Lara S, Graup S, Balk RS, et al. Association between postural balance and anthropometric indexes in elementary schoolchildren. Rev Paul Pediatr 2017;36(01):7

48 Olchowik G, Czwalik A. Effects of soccer training on body balance in young female athletes assessed using computerized dynamic posturography. Appl Sci (Basel) 2020;10(03):1003

49 Perrin P. Equilibration, proprioception et sport. In: Médecine du sport: Pour le Praticien. 2020:60-65. Available at: https://books.google.com.lb/books?id=IYLQDwAAQBAJ. Accessed August 31, 2020

50 Pletcher ER, Williams VJ, Abt JP, et al. Normative data for the NeuroCom sensory organization test in us military special operations forces. J Athl Train 2017;52(02):129-136

51 Stanek E, Truszczyńska A, Drzał-Grabiec J, Tarnowski A. Postural balance assessment in children aged 7 to 9 years, as related to body weight, height, and physical activity. Biomed Hum Kinetics 2015;7:135-141

52 Perrin P, Deviterne D, Hugel F, Perrot C. Judo, better than dance, develops sensorimotor adaptabilities involved in balance control. Gait Posture 2002;15(02):187-194

53 Mallinson AI, Kuijpers ACM, Van Zwieten G, Kakal J, Mullings W, Longridge NS. Computerized dynamic posturography does not detect measured CVEMP and OVEMP abnormalities. Gait Posture 2019;67:248-250

54 Jacobson GP, McCaslin DL, Piker EG, Gruenwald J, Grantham SL, Tegel L. Patterns of abnormality in cVEMP, oVEMP, and caloric tests may provide topological information about vestibular impairment. J Am Acad Audiol 2011;22(09): 601-611 